\title{
Dried leaf extract of Olea europaea ameliorates islet-directed autoimmunity in mice
}

\author{
Tamara Cvjetićanin ${ }^{1}$, Djordje Miljković ${ }^{1}$, Ivana Stojanović ${ }^{1}$, Dragana Dekanski ${ }^{2}$ \\ and Stanislava Stošić-Grujičić ${ }^{1 *}$ \\ ${ }^{1}$ Department of Immunology, Institute for Biological Research 'Siniša Stanković', University of Belgrade, Bulevar Despota Stefana \\ 142, 11060 Belgrade, Serbia \\ ${ }^{2}$ Biomedical Research, R\&D Institute, Galenika a.d., Belgrade, Serbia
}

(Received 11 August 2009 - Revised 29 October 2009 - Accepted 11 November 2009 - First published online 22 December 2009)

The health-promoting effects of various constituents of the olive tree (Olea europaea) are mainly associated with hypoglycaemic and insulinsensitising activities and have been widely demonstrated in the metabolic syndrome and type 2 diabetes. However, their biological activity in autoimmune type 1 diabetes (T1D) is poorly characterised. Therefore, the influence of $O$. europaea-derived components present in dry olive leaf extract (DOLE) was examined in two established preclinical models of human T1D, which differ in some aspects of diabetogenesis: multiple low-dose streptozotocin-induced diabetes in susceptible C57BL/6 and CBA/H mouse strains; cyclophosphamide-accelerated diabetes in non-obese diabetic mice. In both T1D models, in vivo administration of DOLE significantly reduced clinical signs of diabetes (hyperglycaemia and body weight loss) and led to complete suppression of histopathological changes in pancreatic islets. In line with these, insulin expression and release were restored in DOLE-treated mice. Interestingly, inducible NO synthase expression and NO production were significantly elevated in peripheral tissues but were down-regulated within the local environment of the endocrine pancreas. This interference was reflected in NO-mediated suppression of $\mathrm{T}$ lymphocyte proliferation and lower production of the proinflammatory cytokines interferon- $\gamma$, IL-17 and TNF- $\alpha$ in the spleen, with subsequent blockade of $\beta$-cell destruction. The results suggest that DOLE interferes with development of autoimmune diabetes by downregulating production of proinflammatory and cytotoxic mediators. Therefore, the potential use of a DOLE-enriched diet for prophylaxis/treatment of human T1D, and possibly other autoimmune diseases, is worthy of further investigation.

Type 1 diabetes: Olea europaea leaves: Cytokines: Nitric oxide

The term diabetes mellitus is used to describe a variety of chronic metabolic disorders characterised by elevated blood glucose levels now afflicting $3 \%$ of the world population ${ }^{(1,2)}$. Diabetes mellitus can broadly be classified into two main types based on individual aetiologies. Type 1 diabetes (T1D) that accounts for approximately $5-10 \%$ of all cases of diabetes, is an inflammatory autoimmune disease in which pancreatic insulin-producing $\beta$-cells are selectively destroyed by cells of the immune system ${ }^{(3)}$ culminating in a state of hypoinsulinaemia and hyperglycaemia ${ }^{(4)}$. Type 2 diabetes (T2D) that is estimated to represent $90-95 \%$ of all cases is due to $\beta$-cell failure or various degrees of insulin resistance ${ }^{(5)}$. The only possible cure for T1D is control of the $T$ cell autoimmunity against $\beta$-cells together with recovery and/or replacement of the destroyed $\beta$-cell mass. Over many years, various immunomodulatory regimens were tested with the aim of blocking autoimmunity against $\beta$-cell mass and promoting $\beta$-cell preservation. Despite considerable progress in the management of T1D with conventional drugs, a single effective immune-based therapeutic approach has not been identified so $\operatorname{far}^{(2,6-9)}$. This provides an impetus for the development of new therapeutic strategies using various animal models ${ }^{(10,11)}$. However, any single animal model is unlikely to address the issue of population heterogeneity, so the application of different models has been instructive about many diverse scenarios that might occur in human $\mathrm{T}^{(12)}$.

Benefits of the Mediterranean-style diet have been known for centuries, and it has been traditionally used to prevent and treat different metabolic disorders. Phenolic components of commonly consumed foods, such as red wine and virgin olive oil, or components of other olive (Olea europaea) organs, such as leaves, rich in these constituents, have been shown to possess strong antioxidant and anti-inflammatory properties ${ }^{(13)}$. The chemical composition of dry olive leaf extract (DOLE) is very complex, comprising oleuropein, caffeic acid, luteolin, luteolin-7- $O$-glucoside, apigenin7-O-glucoside, quercetin, chrysoeriol and others ${ }^{(14)}$. Due to

Abbreviations: b.wt., body weight; CY, cyclophosphamide; DOLE, dry olive leaf extract; IFN, interferon; iNOS, inducible NO synthase; i.p., intraperitoneal; MLDS, multiple low-dose streptozotocin; NOD, non-obese diabetic; p.i., post-induction; p.o., per oral; Panc, pancreatic islets; PC, peritoneal cells; PLN, pancreatic lymph nodes; IFN, interferon; Spl, splenocytes; T1D, type 1 diabetes; T2D, type 2 diabetes.

* Corresponding author: Stanislava Stošić-Grujičić, fax + 381112761 433, email duta@eunet.rs 
all these useful active ingredients, olive oil and olive leaf constituents have been used increasingly as complementary and alternative medicine to improve metabolic disorders $^{(15-19)}$. Some of these beneficial effects include reactive oxygen species scavenge, inhibition of LDL oxidation, production of $\mathrm{NO}$, down-regulation of adhesion molecules and inhibition of inflammatory cytokines ${ }^{(20-22)}$. It has also been reported that constituents of olive leaves have antihyperglycaemic and insulin-sensitising activities, suggesting a beneficial metabolic effect in $\mathrm{T} 2 \mathrm{D}^{(23-26)}$. However, the development of therapeutic approaches for T1D has been neglected in favour of efforts to advance therapies for the larger T2D population.

In view of the increasing prevalence, there is a growing need to develop integrated approaches towards prevention and treatment of T1D by exploring potentials offered by traditional phytotherapies as alternative and/or supplementary therapy. Recently, we have shown that DOLE-enriched diet ameliorated central nervous system autoimmunity in rats through reduction of proinflammatory cytokine production, which implied that this extract had a potent immunomodulatory effect ${ }^{(27)}$. Therefore, in the present study we investigated the effects of commercially available standardised DOLE on pancreatic islet (Panc)-directed autoimmunity. For this purpose, we used two models of T1D: cyclophosphamide (CY)accelerated diabetes in non-obese diabetic (NOD) mice ${ }^{(28)}$; multiple low-dose streptozotocin (MLDS)-induced diabetes in susceptible mouse strains ${ }^{(29)}$, because hyperglycaemia and insulitis can be easily induced in a relatively short period of time in a high percentage of animals. In both the disease models, inflammatory autoreactive $\mathrm{T}$ cells and macrophages mediate the autoimmune status, causing islet $\beta$-cell destruction either directly or through secretion of proinflammatory cytokines and free radicals ${ }^{(30)}$. However, in contrast to MLDS-induced diabetes, CY-induced diabetes in NOD mice is based on selective elimination of inhibitory cells that would otherwise prevent development of the disease ${ }^{(28)}$. Therefore, the ultimate translational objective is to use both of these animal models to test the hypothesis that DOLE protects against T1D development and to determine potential mechanisms involved in this protective effect.

\section{Materials and methods}

\section{Reagents}

Standardised to $18-26 \%$ of oleuropein, DOLE EFLA ${ }^{\circledR} 943$ was purchased from Frutarom Switzerland Ltd (Wädenswil, Switzerland). The extract was manufactured from the dried leaves of $O$. europaea L., applying an ethanol $(80 \% \mathrm{~m} / \mathrm{m})$ extraction procedure. After a patented filtration process (EFLA ${ }^{\circledR}$ Hyperpure), the crude extract was dried. Furthermore, stability and microbiological purity were confirmed by the manufacturer. The extract was standardised to $19.8 \%$ of oleuropein content by the manufacturer. It was further phytochemically analysed for the presence of various components in the previous report of Dekanski and collaborators. There it was detected that the extract contained oleuropein $(19.8 \%)$, total flavonoids $(0.29 \%)$, including luteoline-7- $O$-glucoside $(0.04 \%)$, apigenine-7-O-glucoside $(0.07 \%)$ and quercetin $(0.04 \%)$, as well as tannins $(0.52 \%)$ and caffeic acid
$(0.02 \%)^{(14)}$. All other reagents were purchased from Sigma (St Louis, MO, USA) unless otherwise noted.

\section{Type 1 diabetes induction and in vivo treatment protocols}

All experimental procedures were approved by the Institutional Animal Care and Use Committee at the Institute for Biological Research 'Siniša Stanković', University of Belgrade and run in accordance to the requirements of the European Union regarding handling of experimental animals. Specific pathogen-free inbred C57BL/6, CBA/H and NOD/ ShiLtJ mice were provided by the Central Animal House Facility of our institute. Mice were maintained under conventional conditions with free access to a standard laboratory chow and potable water. Animals and feed were regularly checked by appropriate microbiological examinations, which showed that the animals were not infected with common mouse pathogens and that the feed was free of microbiological contamination.

Immunoinflammatory T1D was induced in male mice of the $\mathrm{C} 57 \mathrm{BL} / 6$ and $\mathrm{CBA} / \mathrm{H}$ strains with multiple low doses of streptozotocin (MLDS, $40 \mathrm{mg} / \mathrm{kg}$ body weight (b.wt.), intraperitoneal (i.p.) for five consecutive days) as described previously $^{(31)}$. The mice were age-matched $(8-12$ weeks of age) with b.wt. ranging from 25 to $30 \mathrm{~g}$. Treatment with DOLE was per oral (p.o.) by gavage in $0.2 \mathrm{ml}$ of PBS (100 mg/kg b.wt. per d, divided into two daily doses), or i.p. $(40 \mathrm{mg} / \mathrm{kg}$ b.wt per $\mathrm{d})$, given as a prevention regimen (days $-5-21$ of diabetes post induction (p.i.)) or as a reversal regimen (days 5-21 p.i.). Control MLDS-induced mice were treated with an equivalent amount of vehicle. A group of non-diabetic control mice were treated i.p. with DOLE only. The mice subjected to morphological examination of pancreatic glands and ex vivo analyses were sacrificed on day 15 p.i., unless otherwise stated. Each experimental group used for in vivo analyses consisted of six to seven mice per group, whereas for ex vivo analyses each experimental group had four to five mice per group.

For induction of T1D with CY, nulliparous non-pregnant non-diabetic female NOD mice, 8-10 weeks old (b.wt. range $20-25 \mathrm{~g}$ ) were injected twice with the drug at a dose of $300 \mathrm{mg} / \mathrm{kg} \mathrm{b.wt.,} \mathrm{i.p.,} \mathrm{with} \mathrm{a} 2$-week interval between the injections. DOLE was administered i.p. $(40 \mathrm{mg} / \mathrm{kg}$ b.wt. per d), or p.o. (100 mg/kg b.wt. per d, divided into two daily doses) as a continuous treatment until the end of the experiments, starting $1 \mathrm{~d}$ after the first diabetogenic challenge with CY. Control mice were i.p. administered with an equivalent amount of vehicle or left untreated. The number of mice used for every experiment was seven to sixteen per group.

Both in MLDS- and CY-induced diabetes, blood samples were taken from the tail tip of non-fasting mice for blood glucose determination, with a handheld glucometer (GlucoSure Plus; ApexBio, Hsinchu, Taiwan, ROC). Mice were considered hyperglycaemic when blood glucose concentration exceeded $10 \mathrm{mmol} / \mathrm{l}$ (for MLDS induction) and $8.8 \mathrm{mmol} / \mathrm{l}$ (for CY induction).

The dose of DOLE used in the present study was calculated according to a clinical study in which DOLE at $1000 \mathrm{mg}$ daily (divided in two doses) effectively reduced blood pressure ${ }^{(32)}$. We used the metabolic body size or food intake rather than b.wt. as the criterion for extrapolation of the dosage from 
human subjects to mice ${ }^{(33)}$. The estimated quantity of DOLE expressed per unit of human diet was $20 \mathrm{mg} / \mathrm{g}$ of dry food. For the mouse, this consumption corresponded to a DOLE dose of $100 \mathrm{mg} / \mathrm{kg}$. Moreover, our previous results indicated that a similar amount $(80 \mathrm{mg} / \mathrm{kg})$ was very effective in experimentally induced gastric lesions in rats ${ }^{(14)}$, as well as for preventing experimental autoimmune encephalomyelitis in rats $^{(27)}$.

\section{Histology and immunohistochemistry}

For histological analysis, pancreases were placed in formalin and embedded in paraffin. Five-micrometer sections were prepared from different levels $(200 \mu \mathrm{m}$ apart), stained with haematoxylin and eosin and examined for the presence of mononuclear cell infiltration by light microscopy. Multiple independent sections were analysed at varying depths for each pancreas in a blind fashion. At least twenty islets per pancreas were graded for insulitis according to an arbitrary scale as follows: 0 , intact islets; 1 , area of mononuclear cell infiltration within an islet $<25 \% ; 2,25-50 \% ; 3,>50 \% ; 4$, small retracted islets with some residual infiltrates. The mean score for each group was calculated by dividing the total score by the number of islets examined. Representative islets were photographed using a Zeiss microscope at $200 \times$ magnification.

Immunohistochemical analyses were performed on $5 \mu \mathrm{m}$ paraffin thick transverse sections of pancreas. After deparaffinisation, tissue sections were treated using a microwave antigen retrieval procedure in $0.01 \mathrm{M}$ sodium citrate buffer. After blocking endogenous peroxidase, slides were incubated for $1 \mathrm{~h}$ with the appropriate dilution of primary antibodies, followed by the Rabbit ExtrAvidin peroxidase staining kit according to the manufacturer's instructions. Primary antibodies were rabbit anti-nitrotyrosine (1:500), and rabbit antiinducible NO synthase (iNOS; 1:400). Staining was developed with diaminobenzidine (DakoCytomation, Carpinteria, CA, USA), and sections were counterstained with haematoxylin. A minimum of twenty islets per animal were analysed for each marker.

\section{Cell preparations and culture}

Pancreatic lymph nodes (PLN), spleens, resident peritoneal cells (PC) and pancreata were collected from individual MLDS-induced mice or from CY-induced NOD mice treated with DOLE or its vehicle, on day 15 of diabetes p.i. Resident PC were collected by peritoneal lavage with cold PBS. To isolate PLN cells and splenocytes $(\mathrm{Spl})$, organs were mechanically disrupted, passed through $40 \mu \mathrm{m}$ nylon mesh filter and collected by centrifugation. Erythrocytes from single cell suspensions were lysed using erthrocytes lysis buffer (eBioscience, San Diego, CA, USA). Pancreata were used for isolation of the Panc by collagenase digestion, as previously described $^{(12)}$, followed by handpicking. Cell culture supernatants, used for detection of cytokine and NO production were obtained by culturing the cells $\left(1 \times 10^{6} \mathrm{PC}\right.$, $5 \times 10^{6} \mathrm{Spl}$ or $3 \times 10^{6} \mathrm{PLN}$ cells) in twenty-four-well culture plates in $1 \mathrm{ml}$ of Roswell Park Memorial Institute-1640 containing $5 \%$ fetal calf serum, $2 \mathrm{~mm}$-glutamine, $0.01 \%$ sodium pyruvate, $5 \times 10^{-5} \mathrm{M}-2$-mercaptoethanol and antibiotics (culture medium). After $48 \mathrm{~h}$ incubation at $37^{\circ} \mathrm{C}$ in a humidified atmosphere with $5 \% \mathrm{CO}_{2}$, media were harvested for cytokine and NO assay.

\section{In vitro suppression assay}

The in vitro interaction between $\mathrm{PC}$ and Spl was assessed by co-culture. To measure proliferation, Spl $\left(5 \times 10^{5}\right.$ per well) were co-cultured with different numbers of PC $\left(1 \times 10^{3}-1 \times 10^{4}\right)$. Cells were plated in ninety-six-well flatbottom plates in culture medium and stimulated with $1 \mu \mathrm{g} / \mathrm{ml}$ concanavalin A. After $48 \mathrm{~h}$ in co-culture, $37.5 \mathrm{kBq}$ $(1 \mu \mathrm{Ci})$ of $\left[{ }^{3} \mathrm{H}\right]$ thymidine (ICN, Costa Mesa, CA, USA) was added to each well, and cells were harvested $18 \mathrm{~h}$ later. Incorporated radioactivity was measured in a liquid scintillation counter (Beckman Coulter, Fullerton, CA, USA).

\section{Assessment of insulin and cytokines}

For estimation of insulin concentration, non-fasted mice were bled from the orbital plexus. Serum was obtained and examined for mouse insulin using an ELISA kit (Mercodia, Uppsala, Sweden) according to the manufacturer's instructions. Cytokines in both serum and cell culture supernatants were determined by sandwich ELISA using MaxiSorp plates (Nunck, Rochild, Denmark) and antimouse paired antibodies according to the manufacturer's instructions. Samples were analysed in duplicate for murine IL-17, IL-1 $\beta$, TNF- $\alpha$ (BD Pharmingen, San Diego, CA, USA), IL-6, IL-10 (eBioscience), interferon (IFN)- $\gamma$ and IL-4 (R\&D, Minneapolis, MN, USA). The results were calculated using standard curves made on the basis of known concentrations of the appropriate recombinant cytokines.

\section{Assay of nitric oxide release}

Nitrite accumulation, as an indirect measure of NO release, was determined in cell culture supernatants using the Griess reaction. In brief, triplicate aliquots of cell-free supernatants were mixed with an equal volume of Griess reagent (a 1:1 mixture of $0.1 \%$ naphthylethylenediamine dihydrochloride and $1 \%$ sulphanilamide in $\left.5 \% \quad \mathrm{H}_{3} \mathrm{PO}_{4}\right)$. The absorbance at $570 \mathrm{~nm}$ was determined in a microplate reader (LKB 5060-006; LKB, Vienna, Austria) and compared to a standard curve for $\mathrm{NaNO}_{2}$.

\section{$R N A$ isolation and real-time PCR}

Total RNA was extracted from a pool of freshly isolated Spl, PLN cells and PC $\left(5 \times 10^{6}\right)$ or Panc from each experimental group using a mi-Total RNA Isolation Kit (Metabion, Martinsried, Germany) according to the manufacturer's instructions. RNA $(1 \mu \mathrm{g})$ was reverse transcribed using Moloney murine leukaemia virus RT and random hexamer primers (both from Fermentas, Vilnius, Lithuania). PCR amplification of cDNA ( $1 \mu \mathrm{l}$ per $20 \mu \mathrm{l}$ of PCR) was carried out in an ABI PRISM 7000 Sequence Detection System (Applied Biosystems, Warrington, UK) using SYBRGreen PCR master mix (Applied Biosystems) as follows: $10 \mathrm{~min}$ at $50^{\circ} \mathrm{C}$ for deoxy-uridine triphosphate activation; $10 \mathrm{~min}$ at $95^{\circ} \mathrm{C}$ for initial denaturation of cDNA followed by forty 
cycles ( $15 \mathrm{~s}$ of denaturation at $95^{\circ} \mathrm{C}$ and $60 \mathrm{~s}$ for primer annealing and chain extension step). Primer pairs (Metabion, Munich, Germany) were: IL-17, 5'-GGG AGA GCT TCA TCT GT- $3^{\prime}$ and 5'-GAC CCT GAA AGT GAA GGG-3' (GenBank accession no. NM 010552.3); IFN- $\gamma, 5^{\prime}$-CAT CAG CAA CAA CAT AAG CGT CA- $3^{\prime}$ and $5^{\prime}$-CTC CTT TTC CGC TTC CTG A-3' (GenBank accession no. NM 008337.2); TNF- $\alpha$, 5'-CCA CGT AGC AAA CCA C-3' and 5'-TGG GTG AGG AGC ACG TAG T-3' (GenBank accession no. NM 013693.2); IL-4, 5'-ATC CTG CTC TTC TTT CTC G-3' and 5'-GAT GCT CTT TAG GCT TTC C-3' (GenBank accession no. NM 021283.1); IL-10, 5'-TGT GAA AAT AAG AGC AAG GCA GTG-3' and 5'-CAT TCA TGG CCT TGT AGA CAC C-3' (GenBank accession no. NM 010548.1); IL-1 $\beta, 5^{\prime}$-TGT CGT TGC TTG GTT CTC CTT- $3^{\prime}$ and $5^{\prime}$-GCT GAA AGC TCT CCA CCT CAA TG-3' (GenBank accession no. NM 008361.3); iNOS, 5'-CCA TAA TAC TGG TTG ATG AAC T-3' and 5'-AAG CTA AAT CCT ACC AAA GTG A-3' (GenBank accession no. NM 010927.2); insulin, 5'-CCA TCA GCA AGC AGG TTA T- $3^{\prime}$ and $5^{\prime}$-GGG TGT GTA GAA GAA GCC A-3' (GenBank accession no. NM 008386.3); $\beta$-actin, 5'-GGA CCT GAC AGA CTA CC-3' and 5'-GGC ATA GAG GTC TTT ACG G-3' (NM 007393.2). Data were quantitatively analysed using SDS 2.1 software (Applied Biosystems). The expression of these genes was calculated according to the formula: $2^{-\left(C_{\mathrm{ti}}-C_{\mathrm{ta}}\right)}$, where $C_{\mathrm{ti}}$ is the cycle threshold of the gene of interest and $C_{\mathrm{ta}}$ is the cycle threshold value of $\beta$-actin. The obtained values of the samples from MLDS group were arbitrarily attributed a value of one (an arbitrary unit). The efficiency of real time PCR was in the optimal range of $90-110 \%$ (slope of standard curves 3.1-3.6) for all of the primer pairs used.

\section{Flow cytometry}

Cells $\left(3 \times 10^{5}\right.$ per sample) were stained for surface markers with $0.5 \mu \mathrm{g}$ of fluorescein isothiocyanate conjugate-labelled anti-CD4, anti-CD8 or F4/80 antibody (eBioscience). Treg cells were detected by a Mouse Regulatory $\mathrm{T}$ cell Staining Kit (PE-Cy5 Foxp3 FJK-16s, fluorescein isothiocyanate conjugate CD4, PE CD25) according to the manufacturer's instructions (eBioscience). Appropriate isotype controls with the same fluorophore were used (eBioscience). Stained cells were detected on FACSCalibur and analysed by CellQuest Pro software (BD Biosciences, San Diego, CA, USA).

\section{Statistical analysis}

The results are provided as means and standard deviations. Statistical analysis of differences was made using one-way ANOVA, followed by Student-Newman-Keuls test for multiple comparisons, or Student's $t$-test, as appropriate. The Spearman $\rho$ value was calculated to determine the type of correlation $(-1-0=$ inverse correlation). Differences in diabetes incidence were analysed by Fisher's exact probability test. The statistical package used was Primer, version 1.0 (McGraw-Hill, Columbus, OH, USA). $P<0.05$ was considered to be significant.

\section{Results}

Treatment with dry olive leaf extract reduces clinical signs of multiple low-dose streptozotocin-induced diabetes

Diabetes was induced with MLDS in two T1D-susceptible inbred mouse strains, $\mathrm{C} 57 \mathrm{BL} / 6$ and $\mathrm{CBA} / \mathrm{H}$. In order to avoid direct interference with the initial streptozotocin action upon $\beta$-cells by DOLE, i.p. treatment with the extract was started $24 \mathrm{~h}$ after completion of MLDS administration (reversal regimen). Control mice that were challenged with MLDS and received vehicle i.p., developed persistent late onset hyperglycaemia over a 2-week period after MLDS injections (Fig. 1(a) and (b)). Although MLDS induced different degrees of hyperglycaemia in the two mouse strains, DOLE treatment $(40 \mathrm{mg} / \mathrm{kg}$ b.wt.) led to a clear reduction in blood glucose levels in both strains (Fig. 1(a) and (b)). The extract showed a similar protective effect when given p.o. (100 mg/kg b.wt. per d, divided into two daily doses; Fig. 1(a)). Moreover, in mice treated with DOLE by a preventive regimen, diabetes was avoided (not shown). In addition, when a control non-diabetic group of mice was treated with DOLE i.p. for 5 weeks, the animals remained normoglycaemic for the entire period of observation (not shown), indicating that DOLE acts via the immune system, rather than through metabolic pathways. Importantly, prolonged treatment (for 7 weeks) with the extract appeared to be well tolerated by the mice as judged from their behaviour and general appearance (data not shown). Moreover, DOLE treatment did not affect b.wt. gain of treated mice (Fig. 1(c)), suggesting that the extract does not induce toxicity in mice.

\section{The effects of dry olive leaf extract on pathohistological changes and insulin gene expression in the pancreas and on insulin concentration in the serum}

Concordant with the clinical status, histological examination of pancreatic specimens showed that administration of DOLE abrogated the development of the MLDS-induced destructive autoimmune process. Whereas most of the islets of control diabetic mice exhibited insulitis (mean grade1.7 at day 15 p.i.) and subsequently lost clear margins as a result of $\beta$-cell depletion (mean grade 2.6 at day 42 p.i.; Fig. 2(a)), at the end of the study the islets of DOLE-treated mice appeared normal, with no signs of inflammation or destruction (Fig. 2(b)). The mean histological grade of DOLE-treated mice did not exceed 0.5 during the whole investigation period. Also, the total number of islets was reduced in control diabetic mice, when compared with DOLE-treated mice (data not shown). In agreement with pathohistological findings, a decrease in the expression of insulin transcripts, as well as lower systemic insulin levels were found in vehicle-treated $v$. DOLE-treated mice (Fig. 2(c) and (d)).

Dry olive leaf extract counteracts accelerated diabetogenesis induced by cyclophosphamide challenge in non-obese diabetic mice

Since CY-induced diabetes in NOD mice differs in many aspects from MLDS-induced diabetes, mainly due to the selective effect of the compound on Treg function ${ }^{(28)}$, we further examined whether DOLE has a beneficial effect in this 

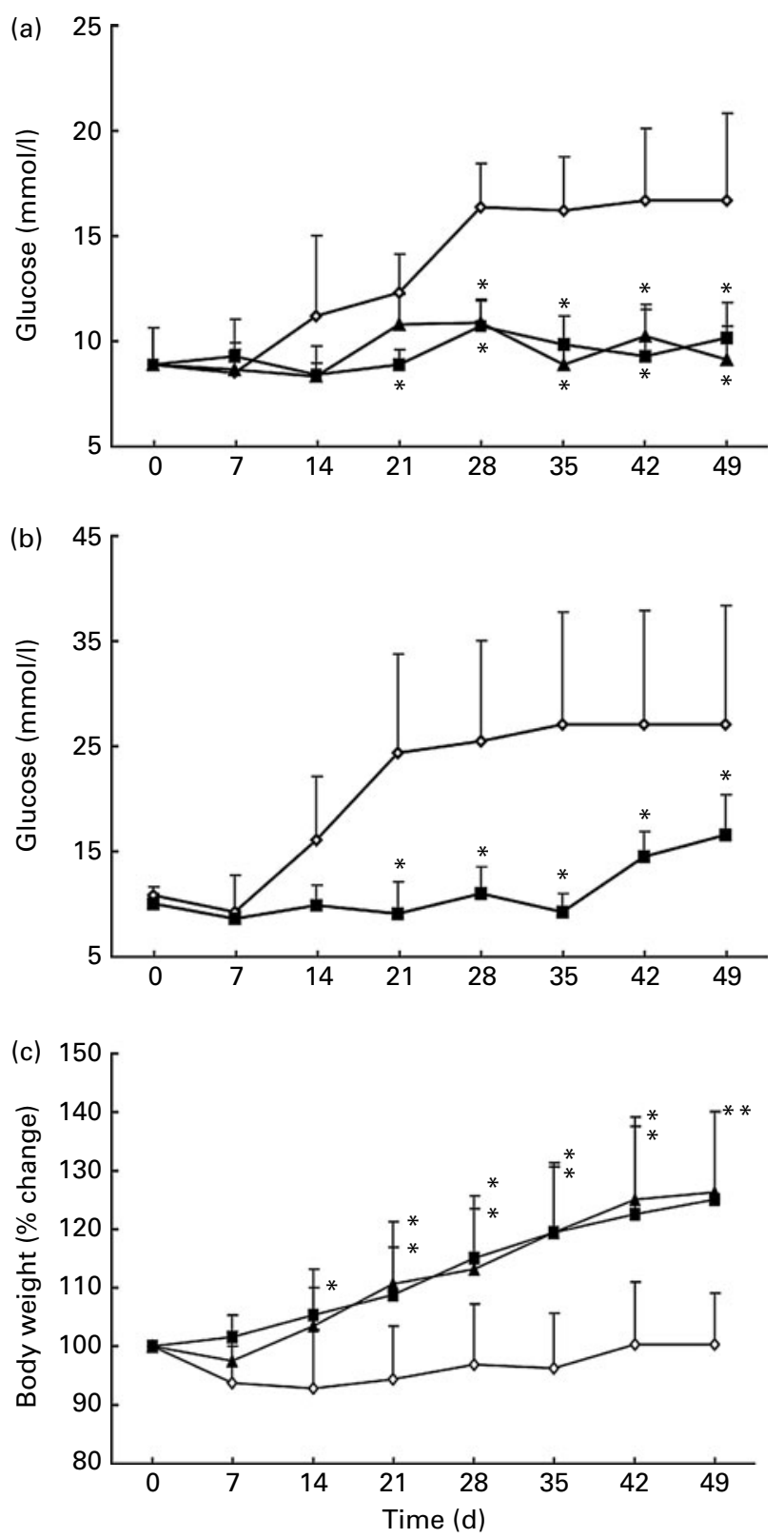

Fig. 1. Effect of dry olive leaf extract (DOLE) treatment on hyperglycaemia and body weight (b.wt.) of multiple low-dose streptozotocin (MLDS)-treated mice. (a) Plasma glucose levels in control CBA/H mice or (b) C57BL/6 mice, receiving MLDS (40 mg/kg per $\mathrm{d}$ for five consecutive days), or mice treated with MLDS and DOLE, administered intraperitoneally (i.p.) or per orally (p.o.) from days 5 to 21 . (c) Percentage change in b.wt. from the start of the experiment determined in the mice described in (a). Results from a representative experiment are presented as the means and standard deviations for six to seven mice per group. ${ }^{*} P<0.05$ refers to corresponding control MLDS mice. (a) $-\diamond-$, MLDS; $-\mathbf{\square}-$, MLDS + i.p. DOLE; $-\mathbf{\Delta}-$, MLDS + p.o. DOLE. (b) $-\diamond-$, MLDS; $-\square-$, MLDS + i.p. DOLE. (c) $-\diamond-$, MLDS; $-\square-$, MLDS + i.p. DOLE; $-\mathbf{\Lambda}-$, MLDS + p.o. DOLE.

model of autoimmune diabetogenesis, as well. As expected, approximately $80 \%$ of the control mice treated with vehicle developed an acute form of diabetes within 2 weeks of the CY injections (Table 1). In contrast, DOLE treatment, given either i.p. or by oral gavage every day from day 1 of CY treatment, completely abolished the diabetogenic process, since none of the DOLE-treated mice developed hyperglycaemia (Table 1). Concurring with the clinical findings, histological studies of pancreases showed that DOLE treatment reduced the extensive leucocyte infiltration observed in mice treated (a)

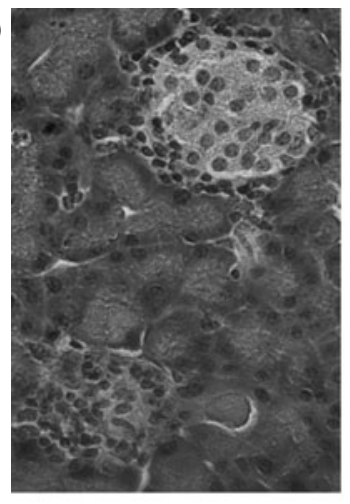

(b)

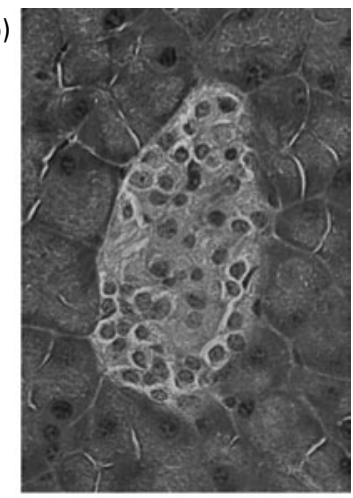

(c)

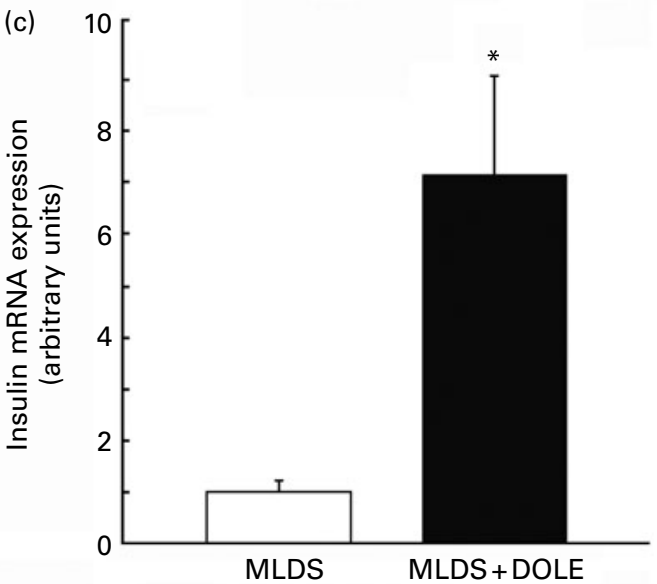

Fig. 2. Histopathology and insulin expression of pancreatic islets (Panc) and serum insulin of multiple low-dose streptozotocin (MLDS)-treated mice. ( $a$ and $b$ ) Light micrographs showing morphological profiles of Panc by day 42 after disease induction (haematoxylin and eosin staining): (a) control MLDSinduced and (b) dry olive leaf extract (DOLE)-treated MLDS-induced C57BL/6 mice. (c) Insulin gene expression and (d) serum insulin concentration in mice described in Fig. 1(b), sacrificed on day 15 post induction. Gene expression is presented in arbitrary units, and the actual value $\left(2^{-\left(C_{\mathrm{ti}}-C_{\mathrm{ta}}\right)}\right)$ for the gene expression was 0.013 . Results from a representative experiment are presented as the means and standard deviations for four to five mice per group. ${ }^{\star} P<0.05$ refers to corresponding control MLDS mice. 
Table 1. Inhibition of diabetes by dry olive leaf extract (DOLE) in cyclophosphamide (CY)-treated non-obese diabetic mice (NOD)*

\begin{tabular}{lccc}
\hline & \multicolumn{3}{c}{ Diabetes incidence } \\
\cline { 2 - 4 } Treatment with DOLE & Diabetic/total & $\%$ & $P \dagger$ \\
\hline DOLE p.o.f & $0 / 9$ & 0.0 & 0.0003 \\
DOLE i.p. & $0 / 7$ & 0.0 & 0.0005 \\
Non-treated\| & $11 / 14$ & 78.6 & \\
Vehicle i.p. & $13 / 16$ & 81.2 & \\
\hline
\end{tabular}

p.o., per orally; i.p., intraperitoneally.

* Diabetes was induced in euglycaemic female NOD mice by CY, as described in 'Materials and methods', and development of the disease was monitored within 2 weeks post induction of diabetes.

†The incidence of diabetes in each group was compared using Fisher's exact probability test.

¥ The mice were treated with DOLE p.o. ( $100 \mathrm{mg} / \mathrm{kg}$ per $\mathrm{d}$, divided in two daily doses) from the first injection of $C Y$ till the end of the experiment.

$\S$ The mice were treated with DOLE i.p. $(40 \mathrm{mg} / \mathrm{kg}$ per d) from the first injection of $\mathrm{CY}$ till the end of the experiment.

$\|$ The mice were left untreated.

ๆ The mice were treated with vehicle i.p. from the first injection of CY till the end of the experiment.

with vehicle (Fig. 3(a) and (b)). While control mice developed severe destructive insulitis (Fig. 3(a)), either intact islets or stationary peri-insulitis were mostly observed in DOLEtreated mice, as exemplified in Fig. 3(b). Consistent with
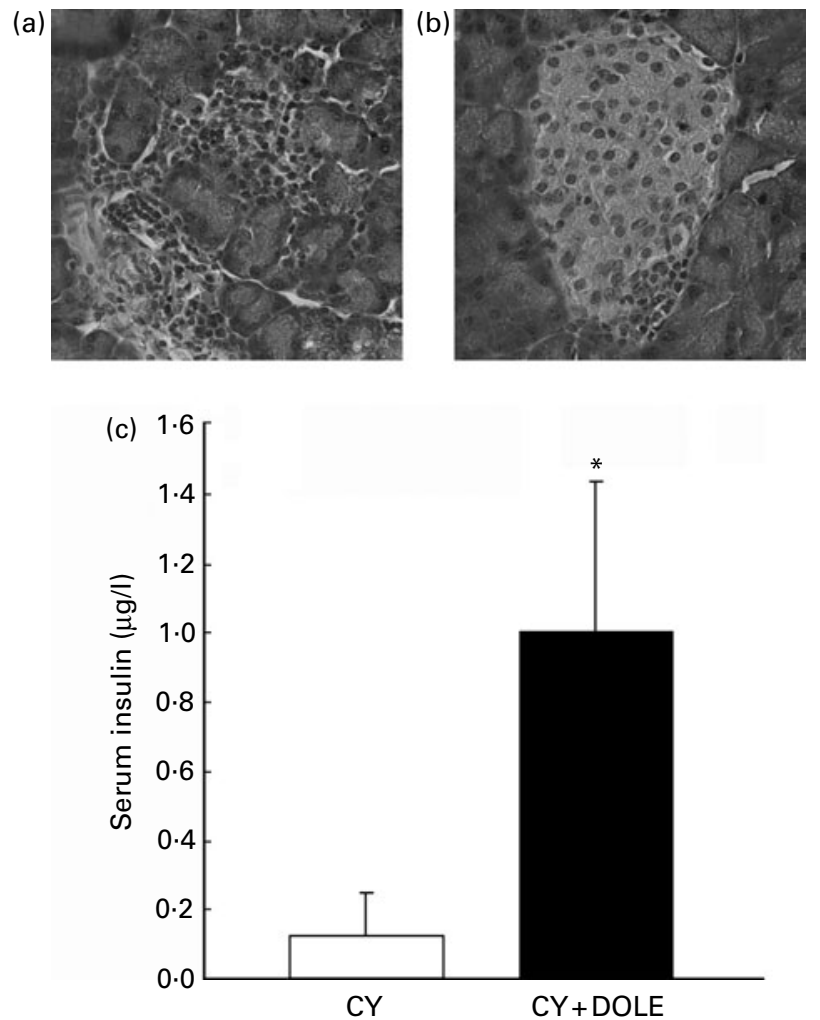

Fig. 3. Histopathology of pancreatic islets and serum insulin of cyclophosphamide (CY)-treated mice. ( $a$ and $b$ ) Representative examples of the light microscopic evaluation of the islets of Langerhans after 2 weeks of CY-accelerated diabetes: (a) vehicle-treated and (b) dry olive leaf extract (DOLE)-treated CY-accelerated non-obese diabetic (NOD) mice. (c) Serum insulin concentration of the mice described in (a) and (b). Results from a representative experiment are presented as the means and standard deviations for four to five mice per group. ${ }^{\star} P<0.05$ refers to corresponding control CY-accelerated NOD mice. these findings, DOLE-treated mice retained their capacity to secrete insulin, as revealed by higher serum insulin concentrations in these animals (Fig. 3(c)).

\section{In vivo treatment with dry olive leaf extract differentially modulates systemic and local nitric oxide production}

To elucidate the mechanisms by which DOLE treatment prevents disease onset, functional ex vivo studies were performed during early progression of the disease induced by CY or MLDS (days 7 and 15 of diabetes induction, respectively) on both peripheral compartments and the pancreas. First, we examined production of NO. In CY-induced NOD mice, the production of $\mathrm{NO}$ by $\mathrm{PC}$ obtained from mice that had received DOLE treatment p.o. was significantly upregulated in comparison with control diabetic mice, as revealed by nitrite formation by these cells (Fig. 4(a)). Similarly, peripheral immune cells, present in the peritoneal cavity, spleen and PLN of DOLE-treated MLDS-induced mice produced much more NO in comparison with cells from vehicle-treated animals (Fig. 4(b)). In line with these results, iNOS expression in peripheral compartments was also significantly higher in mice that had received DOLE compared with vehicle-treated diabetic control mice (Fig. 4(c)). In contrast, nitrite accumulation in cell culture supernatants of the Panc isolated from DOLE-treated mice was significantly reduced when compared with islets of control diabetic mice (Fig. 4(b)), whereas local iNOS staining of pancreatic sections was barely detectable (Fig. 4(d)). Concordantly, immunostaining for nitrotyrosine, a collective marker for oxidative and nitrative stress, was less prominent in pancreata of DOLE-treated $v$. vehicle-treated diabetic mice (Fig. 4(e)).

In vivo treatment with dry olive leaf extract induces in vitro nitric oxide-mediated suppressor function of peritoneal cells

In order to examine whether DOLE-induced up-regulation of peripheral NO production influences $\mathrm{T}$ cell activation, we performed a suppression assay of the conventional $\mathrm{T}$ cell response to mitogen. To this, different concentrations of PC isolated from DOLE-treated or vehicle-treated MLDS-treated mice were co-cultured with normal untreated lymph nodederived lymphocytes stimulated in vitro with concanavalin A. In contrast to PC derived from vehicle-treated mice, PC obtained from DOLE-treated animals displayed dosedependent suppressive effects on $\mathrm{T}$ cell proliferation (Fig. 5(a)). Moreover, a clear negative correlation $(r-0.81$, $P<0.05$; linear regression) was observed between the dosedependent increase in NO production (Fig. 5(b)) and the concomitant reduction in $\left[{ }^{3} \mathrm{H}\right]$ thymidine incorporation (Fig. 5(a)). To determine whether alteration of the PC subsets ratio following DOLE treatment might contribute to the observed suppression of $\mathrm{T}$ cell response, phenotype analysis of cell populations within the peritoneal cavity was performed. Administration of DOLE did not significantly alter the percentage of $\mathrm{CD}^{+}$cells (11.0 (SD 3.0) v. 9.1 (SD 2.6) for control and DOLE-treated mice, respectively) or $\mathrm{CD}^{+}$cells $(8.3$ (SD 1.9) v. 7.7 (SD 2.7) for control and DOLE-treated mice, respectively), but it significantly increased the frequency of F4/80 ${ }^{+}$cells, i.e. macrophages (43.9 (SD 1.6) v. 53.6 (SD 7.0) for control and DOLE-treated mice, respectively; $P=0.040$ ) 

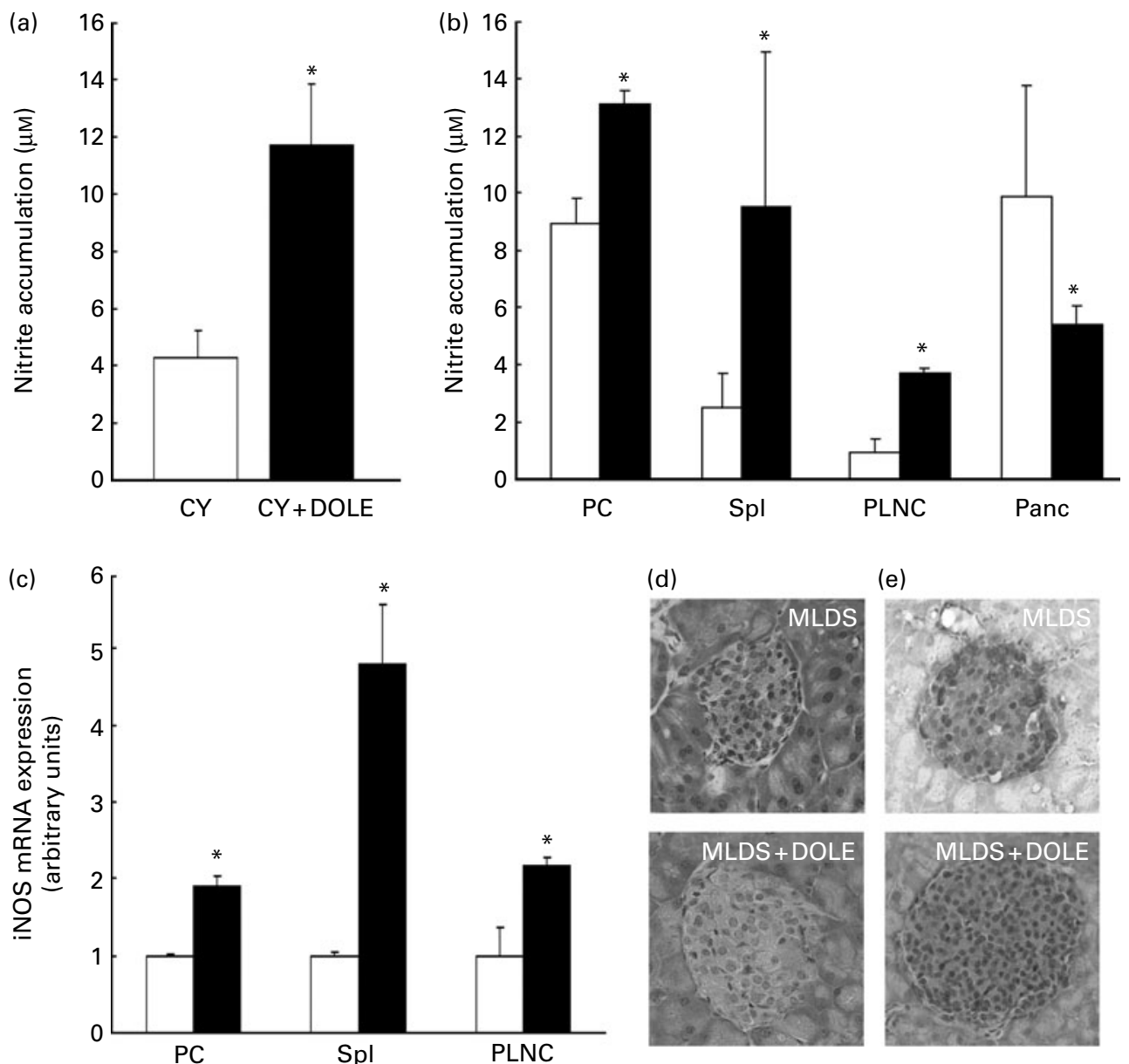

(d)
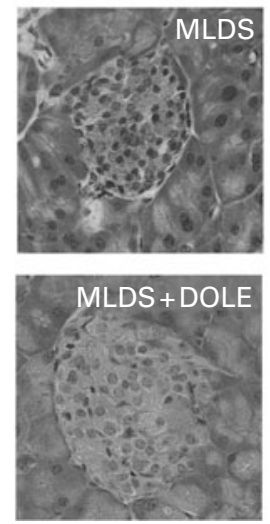

(e)
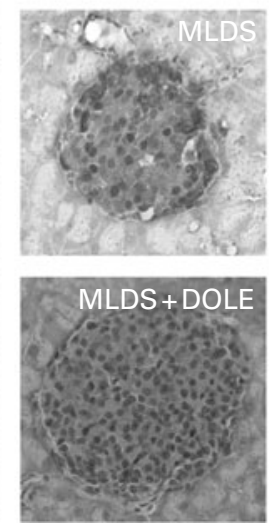

Fig. 4. Effect of dry olive leaf extract (DOLE) treatment on nitric oxide generation in lymphoid tissues and pancreatic islets, inducible nitric oxide synthase (iNOS) expression in lymphoid tissues, presence of iNOS and nitrotyrosine in pancreatic islets (Panc). (a) Peritoneal cells (PC) were isolated from control and DOLE-treated cyclophosphamide (CY)-accelerated non-obese diabetic (NOD) mice and nitrite accumulation was measured in the $48 \mathrm{~h}$ culture supernatants of cells. (b) Nitrite accumulation in the $48 \mathrm{~h}$ culture supernatants of PC, splenocytes (Spl), pancreatic lymph node cells (PLNC) and Panc of control and DOLE-treated multiple low-dose streptozotocin (MLDS)-induced C57BL/6 mice ( $\square$, MLDS; $\mathbf{\square}$, MLDS + DOLE). (c) Inducible NO synthase (iNOS) mRNA expression in the cells of the mice ( $\square$, MLDS; $\mathbf{\square}$, MLDS + DOLE) described in (b). Gene expression is presented in arbitrary units, and the actual values $\left(2^{-\left(C_{\mathrm{ti}}-C_{\mathrm{ta}}\right)}\right)$ for iNOS gene expression were 0.00087 for PC, 0.000093 for Spl and 0.000052 for PLNC (d). Immunostaining for iNOS and (e) nitrotyrosine of Panc of the mice described in (b). $(a-c)$ Results from one of three separate experiments with similar results are given as the means and standard deviations for five mice per group. ${ }^{\star} P<0.05$ refers to corresponding control (a) CY-accelerated NOD mice, or (b and c) MLDS mice.

among PC. Although there was no significant increase in the absolute PC number at the two time points examined, a trend towards greater absolute cell number was noted in the DOLE-treated group (Table 2), suggesting immigration of cells into the peritoneum as an explanation for the increase in absolute cell number.

In vivo treatment with dry olive leaf extract modulates cytokine production

Because proinflammatory cytokines contribute to T1D pathogenesis, we examined whether DOLE treatment may influence MLDS-induced cytokine production in the spleen. Spleens were collected $15 \mathrm{~d}$ after diabetes induction, and cytokine expression and release were assayed ex vivo without further stimulation. The results clearly showed that Spl (Fig. 6(a)) isolated from DOLE-treated mice released significantly reduced amounts of proinflammatory cytokines, including IFN- $\gamma$, IL-17 and TNF- $\alpha$ compared with control diabetic animals. Moreover, we also evaluated cytokine gene expression in both experimental groups and found that IFN- $\gamma$ expression in the spleen of DOLE-treated mice was decreased when compared with that in the vehicle-treated group, whereas there was no significant difference between the two groups regarding the other cytokines examined (Fig. 6(b)). Also, it was important to find out if DOLE had an effect on Treg cell frequency in peripheral lymphoid tissues. To that extent the percentage of $\mathrm{CD}^{+}{ }^{+} \mathrm{CD} 25^{+} \mathrm{FoxP} 3^{+}$ (i.e. Treg) cells among PLN cells was determined in both MLDS- and CY-induced diabetes. DOLE did not induce a significant alteration in Treg percentage in either the MLDS model (11.5 (SD 1.2) v. 9.9 (SD 2.2) for control and DOLE-treated mice, respectively) or the CY model (14.6 (SD 0.6) v. 14.0 (SD 1.6)). Also, the absolute cellularity of PLN was not affected by treatment with DOLE in either MLDS-induced diabetes (Table 2) or CY-accelerated diabetes in NOD mice (1.88 (SD 0.78) v. 1.92 (SD 0.62), in millions, for control and DOLE-treated mice, respectively). 

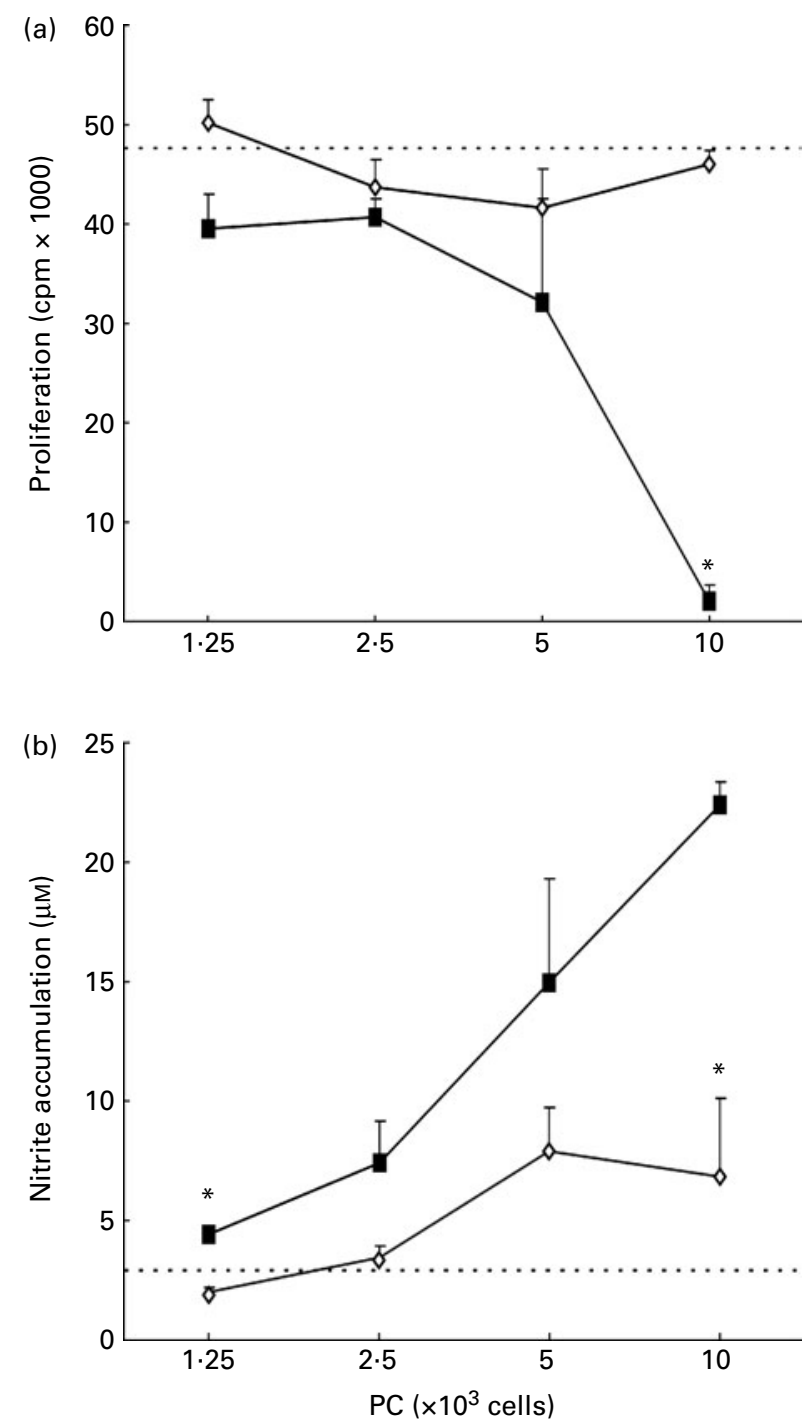

Fig. 5. In vitro suppressor function and nitric oxide generation of peritoneal cells (PC). ( $a$ and $b$ ) PC were collected from dry olive leaf extract (DOLE)treated or vehicle-treated multiple low-dose streptozotocin (MLDS)-induced mice on day 15 of diabetes post induction. These cells were co-cultured a the indicated concentrations with $3 \times 10^{5}$ cervical lymph node cells (LNC) prepared from healthy untreated mice, along with $1 \mu \mathrm{g} / \mathrm{ml}$ concanavalin $\mathrm{A}$. (a) Proliferation of LNC was assessed $66 \mathrm{~h}$ later by incorporation of $\left[{ }^{3} \mathrm{H}\right.$ ]thymidine over the last $18 \mathrm{~h}$ of culture. Data points show the mean thymidine incorporation counts and standard deviations for triplicate wells $\left(-\diamond_{-}\right.$, MLDS; $-\mathbf{-}-$, MLDS + DOLE). (b) Nitrite accumulation in the culture supernatant was measured after $48 \mathrm{~h}$ of cultivation. Horizontal line: LNC alone. ${ }^{\star} P<0.05$ refers to corresponding control MLDS mice. cpm, Cycles per minute.

\section{Discussion}

The present study is the first demonstration that O. europaeaderived components, present in DOLE, confer protection from T1D by interfering with an islet-directed autoimmune response. This interference was reflected in NO-mediated suppression of $\mathrm{T}$ lymphocyte proliferation and lower production of proinflammatory cytokines (TNF- $\alpha$, IFN- $\gamma$ and IL-17) in the peripheral lymphoid compartments as well as less oxidative and nitrative damage within the pancreas.

Olive tree constituents have long been known as anti-diabetic herbal agents in the metabolic syndrome and
Table 2. Effect of dry olive leaf extract (DOLE) on peritoneal cell and pancreatic lymph node cell number

(Mean values and standard deviations)

\begin{tabular}{|c|c|c|c|c|}
\hline & \multicolumn{4}{|c|}{ Treatment group } \\
\hline & \multicolumn{2}{|c|}{ MLDS $^{*}$} & \multicolumn{2}{|c|}{ MLDS + DOLE† } \\
\hline & Mean & SD & Mean & SD \\
\hline \multicolumn{5}{|c|}{ PC $\neq\left(\times 10^{6}\right) /$ mouse } \\
\hline Expt 1 & $3 \cdot 8$ & 1.9 & $5 \cdot 5$ & $2 \cdot 3$ \\
\hline Expt 2 & $3 \cdot 4$ & $1 \cdot 1$ & $4 \cdot 3$ & 0.5 \\
\hline Expt 3 & 3.4 & $2 \cdot 6$ & 4.4 & 1.8 \\
\hline \multicolumn{5}{|c|}{ PLNC $\ddagger\left(\times 10^{6}\right) /$ mouse } \\
\hline Expt 1 & $5 \cdot 3$ & $2 \cdot 4$ & $5 \cdot 5$ & 0.8 \\
\hline Expt 2 & $2 \cdot 2$ & 0.8 & 3.6 & 1.4 \\
\hline Expt 3 & 3.0 & 1.0 & $3 \cdot 1$ & 1.9 \\
\hline
\end{tabular}

MLDS, multiple low doses of streptozotocin; PC, peritoneal cells; PLNC, pancreatic lymph node cells; i.p., intraperitoneally; p.i., post induction.

* MLDS was administered i.p. to C57BL/6 mice at a daily dose of $40 \mathrm{mg} / \mathrm{kg}$ per d for $5 \mathrm{~d}$ (four mice per group per experiment).

†DOLE was administered i.p. at a daily dose of $40 \mathrm{mg} / \mathrm{kg}$ per d from day 5 of MLDS diabetes p.i. (four mice per group per expt).

$\ddagger$ Cells were obtained after $14 \mathrm{~d}$ (Expts 1 and 2 ) or $38 \mathrm{~d}$ (Expt 3 ) of diabetes p.i.

T2D, due to their antioxidant ${ }^{(16)}$ and glucose-lowering effects associated with insulin-sensitising activity, increased peripheral glucose utilisation and improved insulin release ${ }^{(25,26,34-37)}$. The anti-diabetic properties of $O$. europaea L. leaf constituents were evaluated in several experimental models of 'toxic' forms
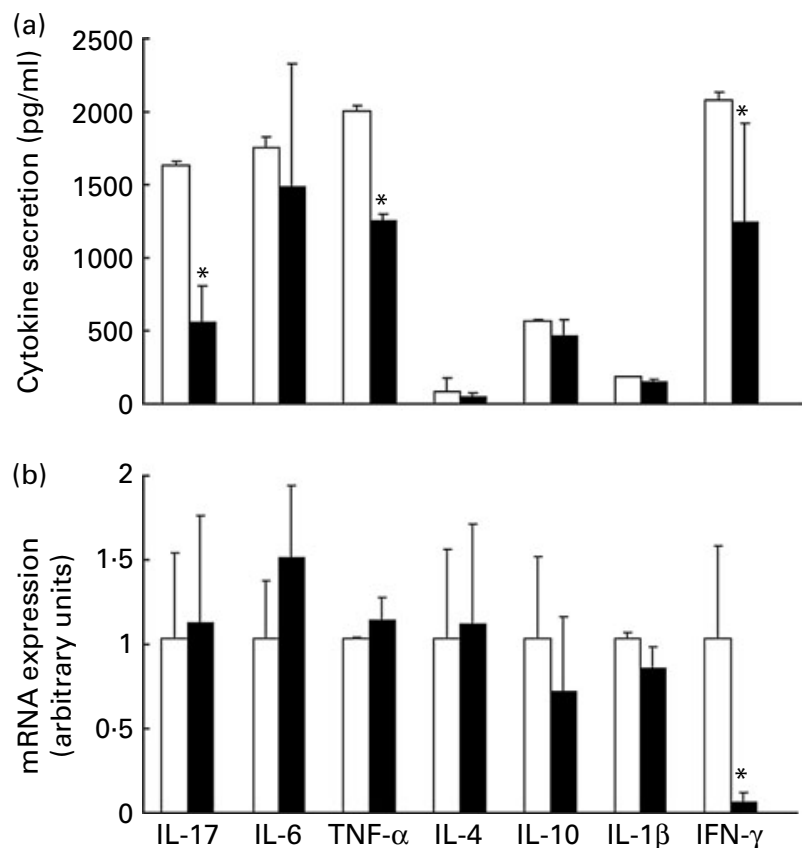

Fig. 6. Effect of dry olive leaf extract (DOLE) treatment on cytokine profile in splenocytes (Spl). Cytokine concentration in culture supernatants ( $\square$, MLDS; 口, LDS + DOLE) (a) and cytokine gene expression (b) of Spl from vehicletreated and DOLE-treated multiple low-dose streptozotocin (MLDS)-induced C57BL/6 mice after $48 \mathrm{~h}$ of cultivation. Gene expression is presented in arbitrary units, and the actual values $\left(2^{-\left(C_{\mathrm{ti}}-C_{\mathrm{aa}}\right)}\right)$ for the analysed cytokines were as follows: 0.000017 for IL-17; 0.000090 for IL-6; 0.0052 for TNF- $\alpha$; 0.000037 for IL-4; 0.00045 for IL-10; 0.013 for IL-1 $\beta ; 0.0021$ for interferon- $\gamma$ (IFN- $\gamma$ ). Data are means and standard deviations of four experiments, each with four to five mice per group. ${ }^{\star} P<0.01$ refers to corresponding control MLDS mice. 
or dietary-induced $\mathrm{T} 2 \mathrm{D}^{(23,24,26,34,38,39)}$. To our knowledge, this is the first study on the effects of $O$. europaea-derived components in T1D in two established mouse models: MLDSinduced immunoinflammatory diabetes; CY-accelerated NOD diabetes. We used the MLDS-induced diabetes model, as the autoimmune process is initiated by minor chemical destruction of $\beta$-cells and shedding of target autoantigens, in contrast to the non-immune 'toxic' form of diabetes induced by a single high dose of streptozotocin. As a consequence, immune cells respond to self $\beta$-cell antigens so progression of hyperglycaemia and insulitis evolves during a 2 -week period ${ }^{(11,29)}$. Alternatively, CY-induced diabetes was used because it is known that the autoimmune response directed against pancreatic $\beta$-cells relies on selective depletion of Treg cells ${ }^{(28)}$. We showed that in both models, DOLE efficiently counteracted diabetogenesis, indicating that the suppressive effect on the islet-directed $\mathrm{T}$ cell immune response is most likely mediated by common events and independently of Treg cells. In support of this is our finding that there was no difference in the frequency of Treg cells within PLN in vehicle- and DOLE-treated mice in which diabetes was induced with CY. The common effect of DOLE in MLDS- and CY-induced diabetes was an increase of NO generation in peripheral lymphoid tissues. This finding is of importance for understanding the beneficial effect of DOLE in diabetes, as it is well known that NO produced in lymphoid tissues has immunoregulatory functions, including anti-proliferative, pro-apoptotic and cytokine-shifting effects on $\mathrm{T}$ cells during their activation ${ }^{(40-42)}$. In addition, PC isolated from DOLE-treated mice, but not PC isolated from vehicle-treated mice, were able to inhibit proliferation of mitogen-activated $\mathrm{T}$ cells. Importantly, the observed inhibition was inversely proportional to the level of NO produced in these co-cultures. One possible explanation for the enhanced capacity of $\mathrm{PC}$ to produce $\mathrm{NO}$ is the observed increase in frequency of cells responsible for its production among $\mathrm{PC}$, i.e. of $\mathrm{F} 4 / 80^{+}$macrophages. Together, our findings suggest that DOLE acts through up-regulation of NO in peripheral lymphoid tissues, which consequently leads to limitation of $\mathrm{T}$ cell activation and finally to restriction of the autoimmune attack upon pancreatic $\beta$-cells. The capacity of DOLE to up-regulate NO generation by lymphoid cells is in accordance with the previously reported amplifying effects of the $O$. europaea bioactive component, oleuropein, on the release of $\mathrm{NO}$ and the expression of iNOS by macrophages during the response to endotoxin challenge in vitro ${ }^{(20)}$. However, several studies showed that $O$. europaea-derived components, such as flavonoids and phenols, are capable of inhibiting inflammation through inhibition of NO production and increasing antioxidant enzyme activity ${ }^{(22,23,35,36)}$. Although, we do not report inhibition of NO production in peripheral compartments by DOLE treatment, we do show that DOLE inhibits NO synthesis in pancreatic $\beta$-cells. This again is very important for the anti-diabetogenic effect of DOLE, as it is recognised that NO released in Panc is mostly cytotoxic and leads to dysfunction and destruction of insulin-producing cells ${ }^{(43,44)}$. Damaging effects of NO may be attributable to the reaction with superoxide anions to yield peroxynitrite, a potent nitrating and nitrosylating agent. Since oxidative stress in diabetes coexists with reduced antioxidant status of the pancreas, which can further increase the deleterious effects of free radicals, it is tempting to speculate that DOLE has a protective effect in diabetes at least partly, through decreasing local oxidative and nitrative damage. Indeed, reduced immunostaining of DOLE-treated Panc for nitrotyrosine, a collective marker for reactive oxygen species and reactive nitrogen species ${ }^{(45)}$, further supported this assumption.

The other important factor influenced by DOLE is the cytokine profile of Spl. We showed that, under the influence of the extract, typical pro-inflammatory cytokines IFN- $\gamma$, TNF- $\alpha$ and IL-17 were down-regulated in MLDS-induced diabetes. On the contrary, anti-inflammatory cytokine (IL-4 and IL-10) generation was unaffected by DOLE. Therefore, it seems that DOLE promotes a profile shift of Spl cytokine production from pro-inflammatory to anti-inflammatory, or from Th1/Th17 to Th2. The importance of Th1 cells and IFN- $\gamma$, as well as of TNF- $\alpha$ for autoimmune diabetes pathology has been described in many papers ${ }^{(44)}$. According to the current understanding of T1D pathogenesis, initial injury to the islets leads to the presentation of exposed autoantigens on antigen-presenting cells to autoreactive $\mathrm{T}$ cells within the regional lymph nodes. The antigen-presenting cells stimulate effector Th1 cells which produce IFN- $\gamma$, and this cytokine activates additional macrophages and polymorphonuclear cells. These cells release IL- $1 \beta, \mathrm{TNF}-\alpha$ and NO, which are directly toxic to $\beta$-cells. Moreover, the antigen-presenting cells promote $\mathrm{CD}^{+} \mathrm{T}$ cells which use FasL, perforin/granzyme and TNF- $\alpha$ to trigger $\beta$-cell apoptosis ${ }^{(44)}$. The role of Th17 cells and their signature cytokine IL-17 in diabetes is still not clear. It has been suggested that Th17 cells are important for the development of diabetes in NOD mice and that IL-17-directed therapy could be useful in the treatment of the disease ${ }^{(46)}$. It has also been shown that islet-reactive Th17 cells primarily function by promoting inflammation, and that their conversion to Th1 cells in lymphopenic hosts results in diabetes ${ }^{(47)}$. Importantly, IFN- $\gamma$ seems indispensable for Th17-induced diabetes, whereas Th17 cells play an accessory role by promoting inflammation produced by Th1 or $\mathrm{CD}^{+} \mathrm{T}$ cells. In the line with these results, in both MLDSinduced and human diabetes, inflammatory infiltrates are composed of both IFN- $\gamma$ - and IL-17-producing cells ${ }^{(12,48,49)}$. Moreover, it was suggested that IL-17 cooperates with TNF- $\alpha$ in inflammation associated with autoimmunity ${ }^{(50)}$. Having in mind all of the findings mentioned above, inhibition of IFN- $\gamma$, TNF- $\alpha$ and IL-17 by DOLE in regional lymphoid tissue, the place of initiation and perpetuation of the diabetogenic process, seem to be a valid explanation for the beneficial effect of the extract in T1D. Importantly, we have recently demonstrated the efficiency of DOLE in experimental autoimmune encephalomyelitis, an animal model of multiple sclerosis $^{(27)}$. There, the application of the extract also led to down-regulation of IFN- $\gamma$ and IL-17 production during the disease course. Thus, it seems that DOLE counteracts pathogenic autoimmune responses dependent on IFN- $\gamma$ and IL-17-producing cells.

The increasing interest in olive tree (O. europaea) constituents is mainly attributed to its antioxidant effects, due to the high concentration of phenolic compounds. In addition to their activities as antioxidants, some phenolics have been shown to possess anti-inflammatory activity ${ }^{(22)}$. This is supported by experiments in which phenolic compounds significantly decreased the production of pro-inflammatory mediators, such as TNF- $\alpha$, IL- $1 \beta$ and PGE $_{2}{ }^{(21,51-53)}$. Feeding NOD mice diets rich in polyphenols derived from grape was 
recently found to decrease the autoimmune inflammatory process associated with $\mathrm{T}_{1} \mathrm{D}^{(53)}$. Here we add that DOLE, rich in phenolic compound oleuropein inhibits inflammation in T1D and protects mice from disease progression. Two observations of particular relevance from the clinical point of view are the apparently low toxicity of DOLE, as demonstrated by the lack of characteristic b.wt. loss that occurs in MLDS-induced diabetes, and the equal efficacy of the extract given either i.p. or p.o. to prevent the disease. Therefore, our finding that DOLE applied orally to mice suppressed T1D, show that oral administration of phenolic compounds could be a feasible way of treating subjects suffering from diabetes. However, the proper evaluation of DOLE efficiency in the treatment of patients with newly diagnosed T1D will require preclinical studies in animals with established disease carried out under a therapeutic regimen of application. Nonetheless, the capacity of DOLE to counteract the diabetogenic effects of MLDS even when applied as a reversal regimen, started $1 \mathrm{~d}$ after the last toxin dose had been given, is encouraging for translation of these findings to a clinical setting.

Regarding DOLE, it has to be emphasised that it is a mixture of various chemicals with potential bioreactivity ${ }^{(14)}$. Therefore, the putative immunomodulating effects of other primary and secondary compounds of DOLE cannot be excluded. Indeed, oleanolic, ursolic and maslinic acids, three main olive leaf triterpenic compounds ${ }^{(54)}$ were recently shown to contribute to the anti-diabetic effect of olive leaves ${ }^{(24,55,56)}$. Further, although as a consequence of gentle processing of olive leaf constituents the phenolic component of DOLE contains almost exclusively oleuropein, it has to be understood that the extract constituents are extensively metabolised in the body. As a consequence, the single phenol products of oleuropein breakdown tyrosol and hydroxytyrosol may contribute to its health-promoting properties, as well. In line with such a possibility, numerous studies have clearly demonstrated that these compounds exhibit beneficial health effects in various oxidative stress associated disorders due to their antioxidant and anti-inflammatory activities $^{(22,35,36,57,58)}$. Therefore, the effect of DOLE on T1D should not be attributed only to the phenolic fraction oleuropein, but also to other components, such as triterpenic compounds (oleanolic acid, maslinic and ursolic acid), tannins and flavonoids, as well as to oleuropein metabolites. To that extent, it is of importance to investigate the individual effect of each compound on the T1D course. However, the obvious advantage of DOLE is that it is an easily attainable product of olive leaves, not requiring purification of any fractions of the extract before application in T1D models, and possibly for human subjects.

In conclusion, we have provided evidence that olive leaf constituents are effective inhibitors of T1D. The results also suggest that the inhibitory effect of DOLE may be due, at least in part, to the NO-mediated suppression of T lymphocyte proliferation and lower production of proinflammatory cytokines (IFN- $\gamma$, IL-17 and TNF- $\alpha$ ) in the spleen, and subsequent blockade of $\beta$-cell destruction. Though the active components and precise mode of action of DOLE are not yet ascertained, its powerful anti-diabetogenic activity, along with the safety profile observed in vivo, suggest that it would be worth undertaking additional studies to explore the possibility that DOLE possesses the desired therapeutic properties applicable to human T1D.

\section{Acknowledgements}

The study was supported by the Serbian Ministry of Science (grant 143029B).The contributions of the authors were as follows: T. C. and I. S. carried out in vivo treatments, conducted glucose, insulin and cytokine analyses, performed real-time PCR and conducted gene expression analyses. D. M. conducted flow cytometry analysis, contributed to data analysis and helped to write the manuscript. D. D. planned and carried out the feeding experiments. S. S.-G. designed the study, performed the cell proliferation assay, conducted histology and immunohistochemistry analyses, coordinated the project and wrote the manuscript. The authors would like to thank Boško Milovanović, Geographical Institute - Serbian Academy of Sciences and Arts for the help with statistical analysis of our data. None of the authors has any conflicts of interest.

\section{References}

1. Gianni C, Mohn A \& Chiarelli F (2009) Technology and the issue cost/benefit in diabetes. Diabetes Metab Res Rev 25, Suppl. 1, S34-S44.

2. Craig ME, Hattersley A, Donaghue TC, et al. (2009) ISPAD clinical practice consensus guidelines 2009 compendium. Definition, epidemiology and classification of diabetes in children and adolescents. Pediatr Diabetes 10, Suppl. 12, $3-12$.

3. Tisch R \& McDevitt H (1996) Insulin-dependent diabetes mellitus. Cell 85, 291-297.

4. Daaboul J \& Schatz D (2003) Overview of prevention and intervention trials for type 1 diabetes. Rev Endocr Metab Dis 4, 317-323.

5. Watson S \& Miller K (2004) Encyclopedia of the Human Body: The Endocrine System. Westport, CT: Greenwood Publishing.

6. Mastrandrea L, Yu J, Behrens T, et al. (2009) Etanercept treatment in children with new-onset type 1 diabetes. Pilot randomized, placebo-controlled, double-blind study. Diabetes Care 32, 1244-1249.

7. Staeva-Vieira T, Peakman M \& von Herrath M (2007) Translational mini-review series on type 1 diabetes: immunebased therapeutic approaches for type 1 diabetes. Clin Exp Immunol 148, 17-31.

8. Kawano Y, Irie J, Nakatani H, et al. (2009) Pioglitazone might prevent the progression of slowly progressive type 1 diabetes. Inter Med 48, 1037-1039.

9. Rother KJ, Brown RJ, Morales MM, et al. (2009) Effect of ingested interferon- $\alpha$ on $\beta$-cell function in children with new onset type 1 diabetes. Diabetes Care 32, 1250-1255.

10. Shoda LK, Young DL, Ramanujan S, et al. (2005) A comprehensive review of interventions in the NOD mouse and implications for translation. Immunity 23, 115-126.

11. Stosic-Grujicic S, Cvetkovic I, Mangano K, et al. (2007) A potent immunomodulatory compound (S,R)-3-phenyl-4, 5-dihydro-5-isoxasole acetic acid, prevents spontaneous and accelerated forms of autoimmune diabetes in NOD mice and inhibits the immunoinflammatory diabetes induced by multiple low doses of streptozotocin in CBA/H mice. J Pharmacol Exp Ther 320, 1038-1049. 
12. Stosić-Grujicić S, Cvjetićanin T \& Stojanović I (2009) Retinoids differentially regulate the progression of autoimmune diabetes in three preclinical models in mice. Mol Immunol 47, 79-86.

13. Perona JS, Cabello-Moruno R \& Ruiz-Gutierrez V (2006) The role of virgin olive oil components in the modulation of endothelial function. $J$ Nutr Biochem 17, 429-445.

14. Dekanski D, Janicijevic-Hudomal S, Tadic V, et al. (2009) Phytochemical analysis and gastroprotective activity of an olive leaf extract. J Serb Chem Soc 74, 367-377.

15. Ramírez-Tortosa MC, Suárez A, Gómez MC, et al. (1999) Effect of extra-virgin olive oil and fish-oil supplementation on plasma lipids and susceptibility of low-density lipoprotein to oxidative alteration in free-living Spanish male patients with peripheral vascular disease. Clin Nutr 18, 167-174.

16. Vissers MN, Zock PL \& Katan MB (2004) Bioavailability and antioxidant effects of olive oil phenols in humans: a review. Eur J Clin Nutr 58, 955-965.

17. Esposito K, Ciotola M \& Giugliano D (2007) Mediterranean diet and the metabolic syndrome. Mol Nutr Food Res 51, $1268-1274$.

18. Fitó M, de la Torre R, Farré-Albaladejo M, et al. (2007) Bioavailability and antioxidant effects of olive oil phenolic compounds in humans: a review. Ann Ist Super Sanita 43, 375-381.

19. Panagiotakos DB \& Polychronopoulos E (2005) The role of Mediterranean diet in the epidemiology of metabolic syndrome; converting epidemiology to clinical practice. Lipids Health Dis $\mathbf{4}, 7$.

20. Visioli F, Bellosta S \& Galli C (1998) Oleuropein, the bitter principle of olives, enhances nitric oxide production by mouse macrophages. Life Sci 62, 541-546.

21. Carluccio MA, Siculella L, Ancora MA, et al. (2003) Olive oil and red wine antioxidant polyphenols inhibit endothelial activation: antiatherogenic properties of Mediterranean diet phytochemicals. Arterioscler Thromb Vasc Biol 23, 622-629.

22. Bitler CM, Viale TM, Damaj B, et al. (2005) Hydrolyzed olive vegetation water in mice has anti-inflammatory activity. $J$ Nutr 135, 1475-1479.

23. Al-Azzawie HF \& Alhamdani MS (2006) Hypoglycemic and antioxidant effects of oleuropein in alloxan-diabetic rabbits. Life Sci 78, 1371-1377.

24. Sato H, Genet C, Strehle A, et al. (2007) Anti-hyperglycemic activity of TGR5 agonist isolated from Olea europaea. Biochem Biophys Res Commun 362, 793-798.

25. Said O, Fulder S, Khalil K, et al. (2008) Maintaining a physiological blood glucose level with 'glucolevel', a combination of four anti-diabetes plants used in the traditional Arab herbal medicine. Evid Based Complement Alternat Med 5, 421-428.

26. Eidi A, Eidi M \& Darzi R (2009) Antidiabetic effect of Olea europea L. in normal and diabetic rats. Phytother Res 23, 347-350.

27. Miljkovic DJ, Dekanski D, Miljkovic Z, et al. (2009) Dry olive leaf extract ameliorates experimental autoimmune encephalomyelitis. Clin Nutr 28, 346-350.

28. Brode S, Raine T, Zaccone P, et al. (2006) Cyclophosphamideinduced type-1 diabetes in the NOD mouse is accelerated with a reduction of $\mathrm{CD} 4{ }^{+} \mathrm{CD} 25^{+} \mathrm{Foxp} 3^{+}$regulatory T cells. J Immunol 177, 6603-6612.

29. Like AA \& Rossini AA (1976) Streptozotocin-induced pancreatic insulitis: new model of diabetes mellitus. Science 193, 415-417.

30. Bach JF (1995) Insulin-dependent diabetes mellitus as a beta-cell targeted disease of immunoregulation. J Autoimmun 8, 439-463.

31. Cvetkovic I, Al-Abed Y, Miljkovic D, et al. (2005) Critical role of macrophage migration inhibitory factor activity in experimental autoimmune diabetes. Endocrinology 146, $2942-2951$
32. Perrinjaquet-Moccetti T, Busjahn A, Schmidlin C, et al. (2008) Food supplementation with an olive (Olea europaea L.) leaf extract reduces blood pressure in borderline hypertensive monozygotic twins. Phytother Res 22, 1239-1242.

33. Rucker RB (2007) Allometric scaling, metabolic body size and interspecies comparisons of basal nutritional requirements. J Anim Physiol Anim Nutr (Berl) 91, 148-156.

34. Gonzalez M, Zarzuelo A, Gamez MJ, et al. (1992) Hypoglycemic activity of olive leaf. Planta Med 58, 513-515.

35. Briante R, Patumi M, Terenziani S, et al. (2002) Olea europea L. leaf extract and derivatives: antioxidant properties. J Agric Food Chem 50, 4934-4940.

36. Visioli F, Poli A \& Galli C (2002) Antioxidant and other biological activities of phenols from olives and olive oil. Med Res Rev 22, 65-75.

37. Jemai H, Bouaziz M, Fki I, et al. (2008) Hypolipidimic and antioxidant activities of oleuropein and its hydrolysis derivative-rich extracts from Chemlali olive leaves. Chem Biol Interact 176, 88-98.

38. Bennani-Kabchi N, Fdhil H, Cherrah Y, et al. (2000) Therapeutic effect of Olea europea var. oleaster leaves on carbohydrate and lipid metabolism in obese and prediabetic sand rats (Psammomys obesus). Ann Pharm Fr 58, 271-277.

39. Coskun O, Kanter M, Korkmaz A, et al. (2005) Quercetin, a flavonoid antioxidant, prevents and protects streptozotocininduced oxidative stress and $\beta$-cell damage in rat pancreas. Pharmacol Res 51, 117-123.

40. Albina JE, Abate JA \& Henry WL Jr (1991) Nitric oxide production is required for murine resident peritoneal macrophages to suppress mitogen-stimulated $\mathrm{T}$ cell proliferation. Role of IFN-gamma in the induction of the nitric oxide-synthesizing pathway. J Immunol 147, 144-148.

41. Bogdan C (2001) Nitric oxide and the immune response. Nat Immunol 2, 907-916.

42. Lemaire G, Guittet O, Vesin MF, et al. (2009) Glutathione depletion reveals impairment of antigen processing and inhibition of cathepsin activity by nitric oxide in antigen-presenting cells. Mol Immunol 46, 1100-1108.

43. Stassi G, De Maria R, Trucco G, et al. (1997) Nitric oxide primes pancreatic beta cells for Fas-mediated destruction in insulin-dependent diabetes mellitus. $J$ Exp Med $\mathbf{1 8 6}$ 1193-1200.

44. Pearl-Yafe M, Kaminitz A, Yolcu ES, et al. (2007) Pancreatic islets under attack: cellular and molecular effectors. Curr Pharm Des 13, 749-760.

45. Ischiropoulos H, Zhu L, Chen J, et al. (1992) Peroxynitritemediated tyrosine nitration catalyzed by superoxide dismutase. Arch Biochem Biophys 298, 431-437.

46. Emamaullee JA, Davis J, Merani S, et al. (2009) Inhibition of Th17 cells regulates autoimmune diabetes in NOD mice. Diabetes 58, 1302-1311.

47. Martin-Orozco N, Chung Y, Chang SH, et al. (2009) Th17 cells promote pancreatic inflammation but only induce diabetes efficiently in lymphopenic hosts after conversion into Th1 cells. Eur J Immunol 39, 216-224.

48. Miljkovic D, Cvetkovic I, Momcilovic M, et al. (2005) Interleukin-17 stimulates inducible nitric oxide synthase-dependent toxicity in mouse beta cells. Cell Mol Life Sci 62, 2658-2668.

49. Tesmer LA, Lundy SK, Sarkar S, et al. (2008) Th17 cells in human disease. Immunol Rev 223, 87-113.

50. Hartupee J, Liu C, Novotny M, et al. (2009) IL-17 signaling for mRNA stabilization does not require TNF receptor-associated factor 6. J Immunol 182, 1660-1666.

51. Blonska M, Czuba ZP \& Krol W (2003) Effect of flavone derivatives on interleukin-1 beta (IL-1 beta) mRNA expression and IL-1 beta protein synthesis in stimulated RAW 264.7 macrophages. Scand J Immunol 57, 162-166. 
52. Miles EA, Zoubouli P \& Calder PC (2005) Differential antiinflammatory effects of phenolic compounds from extra virgin olive oil identified in human whole blood cultures. Nutrition 21, 389-394.

53. Zunino SJ, Storms DH \& Stephensen CB (2007) Diets rich in polyphenols and vitamin A inhibit the development of type 1 autoimmune diabetes in nonobese diabetic mice. J Nutr 137, $1216-1221$.

54. Sanchez-Avila N, Priego-Capote F, Ruiz-Jimenez J, et al. (2009) Fast and selective determination of triterpenoic compounds in olive leaves by liquid chromatography-tandem mass spectrometry with multiple reaction monitoring after microwave-assisted extraction. Talanta 78, 40-48.
55. Jang S-M, Yee S-T, Choi J, et al. (2009) Ursolic acid enhances the cellular immune system and pancreatic beta-cell function in streptozotocin-induced diabetic mice fed a high-fat diet. Int Immunopharmacol 9, 113-119.

56. Liu J, Sun H, Duan W, et al. (2007) Maslinic acid reduces blood glucose in KK-Ay mice. Biol Pharm Bull 30, 2075-2078.

57. Lory D, Incani A, Deiana M, et al. (2009) Protective effect of hydroxytyrosol and tyrosol against oxidative stress in kidney cells. Toxic Ind Health 25, 301-310.

58. Andrikopoulos NK, Kaliora AC, Assimopoulou AN, et al. (2002) Inhibitory activity of minor polyphenolic and nonpolyphenolic constituents of olive oil against in vitro low-density lipoprotein oxidation. J Med Food 5, 1-7. 